\title{
Storytelling Canvas: A visual framework for developing and delivering resonating stories
}

\author{
Sebastian Kernbach \\ Institute of Media and Communication Management, University of St. Gallen, Switzerland \\ Hasso Plattner Institute of Design, Stanford University, United States \\ sebastian.kernbach@unisg.ch
}

\begin{abstract}
In this article, I attempt to bring together key elements of storytelling in a visual framework, the Storytelling Canvas. The Canvas aims to bring together various strategies for developing and delivering resonating stories. The strategies are organized in three stages that are relevant for every story: beginning, middle and end. Before working on the strategies, storytellers need to consider the topic, the audience including their needs and the goal of the story. This framework has been used for managers, academics and students around the world including organizations such as the African Doctoral Academy, University of St. Gallen, Hilti, European Central Bank, Stanford University and others. This article aims to introduce the framework to foster a debate about what constitutes good storytelling in management and academia.
\end{abstract}

Keywords-Storytelling, Canvas, visualization, visual template, framework

\section{INTRODUCTION}

The term storytelling is omnipresent in the (business) world, what started with tribes using stories to pass on knowledge to younger generations and the first visual stories used in the Cave paintings has become ubiquitous as advertising campaigns use stories, presentations should be delivered as stories, new formats such as PechaKucha present stories and the latest development in social media sees the term story at the frontline with Instagram stories, Facebook stories, and WhatsApp stories. But the question remains what makes a story? What are the elements that can help build (business) stories?

Working with stories in communication is not new, however, the strategic application of storytelling to convey content and messages is currently subject a hot topic in many disciplines. Stories convey content and messages on an implicit, subconscious level which requires less effort by the audience compared to facts and statistics. The emotional persuasion conveyed by stories affects not only the left part of the brain, responsible for logic, but all parts of the brain, especially the right part of the brain, responsible for visions and feelings. Stories make the content heard in a complex and overwhelming world that is 'always on' (POPC = permanently online, permanently connected) and people have little attention span but the mechanism of stories have impact despite information overload [1]. In the study called 'Significant Objects', Rob Walker and Joshua Glenn devised a literary and anthropological experiment that demonstrated the effect of narrative on any given object's subjective value can be measured objectively [2].

This paper aims to contribute to the body of research on stories and visualization by proposing a framework of the constitutive elements of storytelling. In this first modest attempt, I aim to map key elements of storytelling onto the Storytelling Canvas.

\section{STORYTELLING IN KNOWLEDGE MANAGEMENT AND ORGANIZATIONAL LEARNING}

Storytelling is used in knowledge management, corporate culture, branding and advertising to engage content and connect it with the audience in a meaningful and memorable way. Within the field of knowledge management, storytelling can be considered as informal practice that facilitates the transfer of tacit knowledge. Storytelling is the sharing of "war stories" in communities of practice and is an important part of action learning [3]. Developing stories has been proposed as an enabler of organizational learning, particularly when dealing with new or unusual situations [4]. The Institute for Knowledge Management offers a definition of a story and its relation to knowledge transfer: a story is "a tiny fuse that detonates tacit understanding in the mind of the listener" [5].

Nonaka and Takeuchi [6] suggest storytelling as an informal process that facilitates the transfer of the tacit dimensions of critical knowledge through internalization and socialization. Stories are assumed to appeal to the experiential system of personality because of their emotional engagement and representation of events in a manner similar to how they are experienced in real life [7]. Thus, stories are essentially more appealing than codified rules and procedures, technical documentation and lectures on abstract subjects. In the persuasion and communication literature, including stories in the message has been shown to increase the persuasiveness of the message [8].

Stories combine both reflective and experiential approaches to learning [4]. Stories trigger reflection 
about "what is going on here?" and serve as mechanisms for experimentation [9] that can create new understanding and meaning through action. Prior experiences captured by stories guide rather than prescribe ongoing action [4]. Stories communicate who did what, when and why and act as thought machines through which individuals test out ideas and feelings about something and try to learn more about it [10]. Stories represent practice, how things are actually done.

The storytelling method, also known as 'learning histories', was developed at MIT in 1995 by a group of researchers, journalists and managers of large corporations [11]. The goal was to find a way to document a collective learning process of all involved employees from particular incidents, such as change processes, and make it available throughout the organization [12]. However, this approach is very comprehensive and requires a large amount of resources, e.g. for a large storytelling project at a bid corporation, it takes four people and 33 working days to apply the rigid process of this storytelling method [13].

As resources are scarce, the proposed Storytelling Canvas suggest an alternative more straight-forward process to help individuals, teams and organizations to engage their content, connect it with the audience and tell a story. The following sections show why visual templates might be beneficial in general and in particular for storytelling as well as introducing the Storytelling Canvas.

\section{THE VALUE OF KNOWLEDGE VISUALIZATION AND VISUAL TEMPLATES}

A visual template provides a graphical structure onto which information and knowledge can be meaningfully mapped and related [14]. Visual templates can support face-to-face and virtual conversations, in which either one person works with the visual template or in a group one person acts as a facilitator and moderates the discussion by documenting the participants' inputs to the templates themselves [15]. Very well-known examples of visual templates are the BCG matrix, the SWOT diagram, or recent developments such as the Meeting Canvas or Empathy Map used in design thinking.

The graphical structure of visual templates, made up of boxes and labels, offers 'affordances' [16] - i.e., cues as to how the visual template could be used in practice. Visual templates carry four particular affordances: infiltrate, spatialize, captivate, and materialize [17]. Infiltrate means that visuals are subjected to less scrutiny than verbal due to the weaker social regulation that applies to visuals in Western culture [18]; spatialize means that visuals are especially well-suited for communicating complex and multidimensional relationships, in addition the spatial setup of visuals allows for bridging of individual elements through composition and positioning [19]; captivate means that the immediacy of perception of visuals has the potential to captivate audiences, more specifically, visuals are perceived rapidly, attract attention quickly, and have the potential to express attitudes and emotions with powerful impact that surpasses a purely cognitive processing of its content whereby audiences become affectively, aesthetically and corporeally engaged [20]; materialize means that visuals give novel ideas tangibility and shape [17]. The materialization of visuals helps overcome language barriers and establishes visuals as a kind of 'global language' [21].

Thus, those affordances make visuals and particular visual templates good candidates to support the development and delivery of stories as they support the structuring and spatially arranging of complex information, allowing for immediacy of perceiving and processing content, and communicating attitude and emotions which engages audiences affectively, aesthetically and corporeally.

\section{THE STORYTELLING CANVAS}

The Storytelling Canvas aims to bring together single elements, recommendations and best practices of storytelling in a single visual framework. The framework consists of two parts, the general conditions and the story elements. The general conditions consist of the topic that the story is about, the identification of the audience and their needs, using the empathy map canvas [22], and the goal that should be achieved by telling the story which is supported by reflecting about what the audience thinks, feels and knows before the story and by anticipating what the audience should think, feel and know after the have been exposed to the story. The story elements consists of an overarching three level structure of beginning, middle and end in line with the three-actmodel of storytelling [23].

\section{A. Beginning}

For the beginning, three elements can be used to create an impactful start which is "start with why" [24], "common ground" and "one big idea" [25]. Start with why helps the storytelling to not get lost in the details of the 'what' and 'how' of the story but to focus on the why of the story, and why as in "why should I (as audience) care?" [26]. In order to answer that question, the storyteller should have done the audience check first and then identify the pains and gains of the audience to address those pains and gains through the why. The second element of the beginning "common ground" refers to connecting to the audience through shared experiences, looking into the past, to identify common events, interests, memories or other forms of history and common goals, looking into the future, to identify a mutually desired vision, outcomes or common view of the (ideal) future. The third element of the beginning is "one big idea" which means that you focus your study on one big idea that is conveying your unique perspective, communicate what is at stake and that you can ideally state in one complete sentence. 


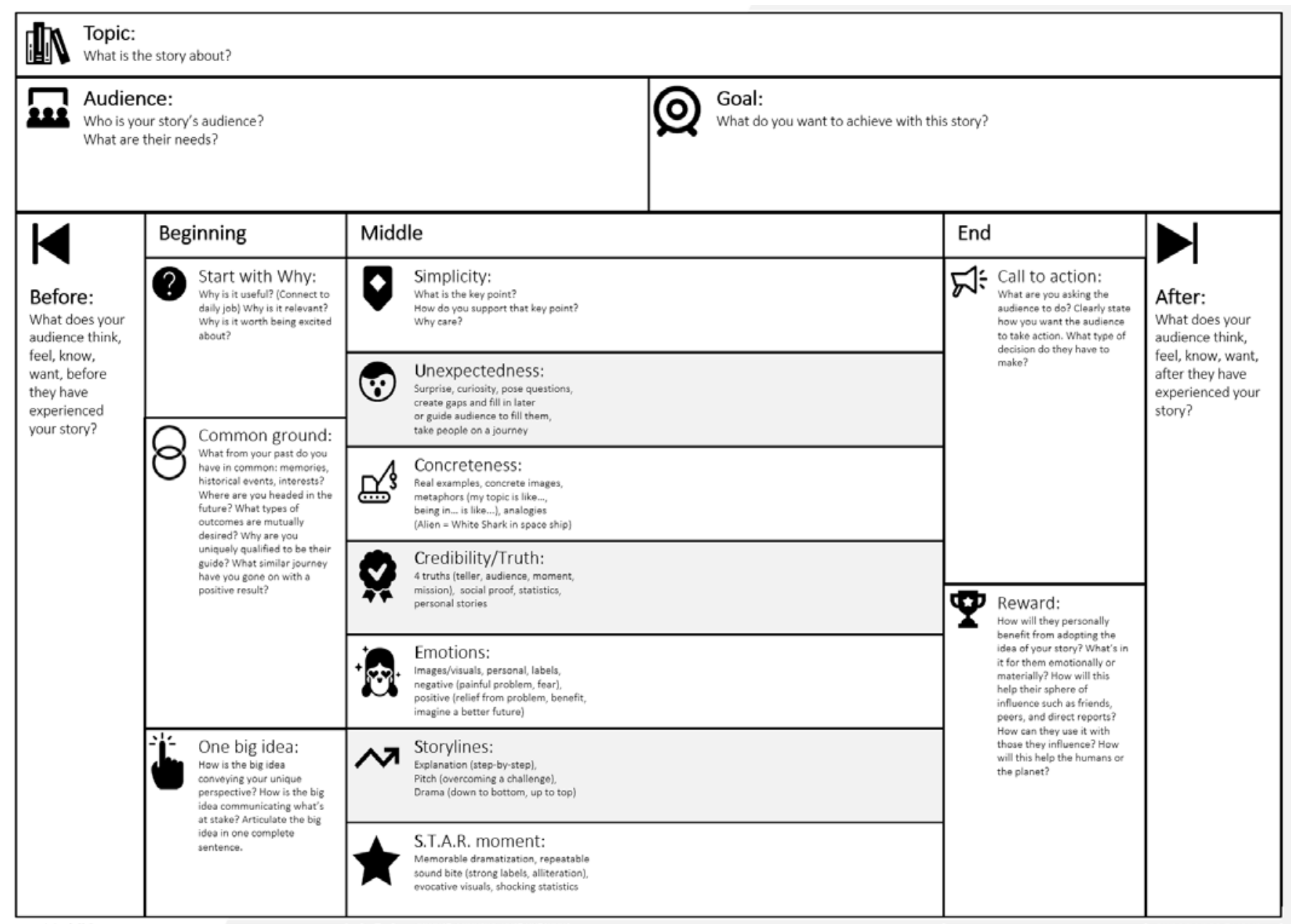

Fig. 1. Storytelling Canvas

\section{B. Middle}

For the middle, the seven elements abbreviated as the SUCCESS formula [27] are adapted to engage the content with the audience and find the right balance of information and emotion [28, 29]. The first five letters SUCCE are in line with the existing approach of Heath and Heath [27] and two new elements are added, S for 'Storylines' and another S for 'S.T.A.R. moments' [25].

The first ' $S$ ' of the SUCCESS formula stands for 'Simplicity' and asks for the key point of the story, and if it is clearly and simply stated. And to the 'rule-of-three' that a piece of argument should be supported by three pieces of evidence as this increases the charismatic appeal of the storyteller [30]. In journalism, it is called 'the lead' and contains the most essential elements of a story, both finding the core and writing the lead are strategies for forced prioritization. Examples are "Apple iPod: 1000 songs in your pocket" or "Southwest Airlines: We are THE low-fare airline". The ' $U$ ' stands for unexpectedness and aims to create curiosity and surprise in the audience by posing critical questions, breaking a pattern or creating gaps that are filled in later which enables the storyteller to take people on a journey. The first ' $C$ ' stands for 'Concreteness' which means turning something abstract into something concrete by using real examples, concrete images or analogies as well as metaphors which also evidence for a charismatic storyteller [30]. For example, by stating 'my topic is like... playing a puzzle, navigating in a labyrinth, or sailing the sea' as well as 'being an employee in my department is like... being a magician, being a fire man or being an entrepreneur'. The second ' $C$ ' stands for 'Credibility' or truth which means using personal stories, quotes from people or organization that are accepted by the audience for social proof and statistics for legitimization of your argument. The ' $E$ ' stands for emotions, where you can refer to both positive emotions, such as joy through benefits, relief of a problem, or imaging a better future, and also negative emotions, such as anger, fear, sadness, or disgust, to bring your message across. Interestingly, the seven basic human emotions cover one positive emotion (joy), one neutral emotion (surprise/curiosity) and five negative emotions (anger, fear, disgust, contempt, sadness) [31]. For a more distinguished choice of positive emotions to evoke through stories, please refer to Ekman's 16 enjoyable emotions: taste, smell, touch, sight, hearing, excitement, relief, wonder, ecstasy/bliss, fiero (pride in achievement), naches (pride of parent/mentor), Schadenfreude, elevation, gratitude, and two more [32]. The second ' $S$ ' stands for 'Storyline' and distinguishes four types of basic stories: descriptive, explicative, argumentative, and narrative [33] which have been adapted by Dan Roam into Report, for 
describing facts, Explanation, for explicative, Pitch, for argumentative, and Drama, for narrative [34]. In a very narrow sense, one could argue that only the narrative is a real story while the others are other genres of communication while in a broader sense of storytelling, all four types can be seen as stories. The last ' $S$ ' stands for 'S.T.A.R. moment', which is an acronym for 'Something They'll Always Remember', and can come along in the form of a memorable dramatization, a repeatable soundbite, evocative visuals, shocking statistics, or a strong label in form of an alliteration [25].

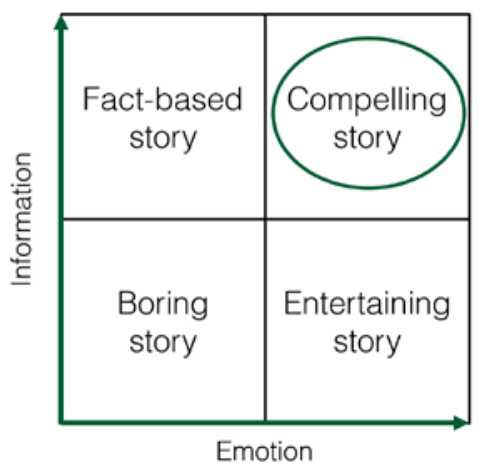

Fig. 2. Good stories contain the right combination of emotion and information

These seven strategies for the middle to 'make the point' help storytellers to focus on the essential of the story and engage the content in a way that is meaningful and memorable for the audience using the appropriate combination of information and emotion.

\section{End}

For the end, two elements can be used to give the story a good finish. The first one is the identification of the 'Reward' which should appeal to the needs of the audience. This reward is organized in three ways: benefit to audience, benefit to sphere and benefit to mankind. The benefit to audience should explain how they will personally benefit from adopting the idea conveyed in the story or what is in it for them materially or emotionally. The benefit to sphere should explain how the idea of the story will benefit friends, peers or direct reports and how the audience can use the benefit to influence those in their sphere. The benefit to mankind should explain how the idea of the story will help humans or the planet which also called "appeal to higher ambition” in research on charisma [30]. The second element of a good finish is the 'Call to action'. In the call to action, storytellers need to finish with a concrete invitation to do something. The type of call depends on who is sitting in your audience, there are four distinct type to distinguish: doer, supplier, influencer, innovator [25]. In a call to action, storyteller ask the doer to make decisions, respond or attempt, suppliers to acquire, fund, or provide resources, the influencer to activate, empower or promote your idea, and the innovator to create, discover or pioneer in a new way.

\section{DISCUSSION}

When delivering a story, storytellers can benefit from research on charismatic appeal that integrates six strategies to appear more charismatic. The before mentioned rule-ofthree, the use of analogies and metaphor, the appeal to higher ambition and in addition, when delivering the story, using a low voice, both for male and female storytellers, using gestures to connect with the audience and making conscious breaks to gain momentum [30].

In addition to the Storytelling Canvas, storytellers can also make use of Hollywood story structures, plot types, character archetypes and types of conflict. Hollywood story structures have, like the Storytelling Canvas, one thing in common which is the 3-act-structure [23, 35]. Whether this is the classical three-act-structure consisting of expositionconfrontation-resolution, or the hook-problem/solutionconclusion, or the hero journey consisting of departureinitiation-return [36], they all have beginning, middle and end. Most of them follow the peak-end-rule identified by Kahneman that stories are best remembered if they have one emotional highlight and a meaningful end [37]. While the three part structure of every structure seems simple, it can get often very complex, especially when looking at the 17 elements with the three parts of the hero journey [36]. However, a group of researchers analyzed hundreds of stories and found that most movies can be reduced to the essential which is rise (happiness) and fall (unhappiness) and therefore be categorized into six basic plot types: rags to riches, riches to rags, man in a hole, Icarus, Cinderella, Oedipus [38]. In addition to the story structures and the six basic plot types, every story in Hollywood has in common that they have a protagonist, an acting subject and other characters archetypes. Campbell has summarized eight and a half character archetypes: protagonist, antagonist, mentor, manipulator, sidekick, sceptic, emotional, logic and love interest [36]. In addition, every story has a conflict. Three types of conflict have been established which are: intrapersonal conflict, also known as man vs. self, inter-personal conflict, also known as man vs. man, and global conflict, also known as man vs. nature [23].

Many stories fall short as they underestimate the identification of the right audience and empathizing with their needs. In order to identify the right audience, storytellers can start by using stakeholder maps [39] to better understand the larger context of the audience as well as using personas [40], used in design thinking, to make the audience more concrete.

Knowing which strategies can be used to develop and deliver a resonating story can also help overcoming the constrains of PowerPoint [41], might help to create visualizations for more attention and retention of the content by the audience [42] and help design thinking students and professionals to convey their insights of being empathetic with the user supporting insight and foster action for ideation and the creation of prototypes [43]. 


\section{CONCLUSION}

Stories are omnipresent in the world as they warrant more attention and buy in from the audience. However, the elements of good storytelling are fragmented and have so far not been put together. In this article, the Storytelling Canvas is proposed as a first attempt to bring together the core elements of storytelling. This hopefully invites scholars and practitioners to think about the key elements of storytelling and how individuals, teams and organizations can employ those elements to develop and deliver meaningful and memorable stories.

\section{REFERENCES}

[1] Schach, A. (Ed.). (2017). Storytelling: Geschichten in Text, Bild und Film. Springer-Verlag.

[2] Glenn, J., \& Walker, R. (Eds.). (2012). Significant objects. Fantagraphics Books.

[3] Connell, N.A.D., Klein, J.H. and Mayer, E. (2004), "Narrative approaches to the transfer of organizational knowledge”, Knowledge Management Research and Practice, Vol. 2 No. 3, pp. 184-193.

[4] Garud, R., Dunbar, R.L. and Bartel, C.A. (2011), "Dealing with unusual experiences: a narrative perspective on organizational learning”, Organization science, Vol. 22 No. 3, pp. 587-601.

[5] Sole, D. and Wilson, D.G. (2002), Storytelling in Organisations: The Power and Traps of Using Stories to Share Knowledge in Organisations, LILA Harvard University, New York, NY, pp. 1-9.

[6] Nonaka, I. and Takeuchi, H. (1995), The KnowledgeCreating Company: How Japanese Companies Create the Dynamics of Innovation, Oxford University Press, New York, NY.

[7] Epstein, S. (1994), "Integration of the cognitive and the psychodynamic unconscious”, American Psychologist, Vol. 49 No. 8, pp. 709-724.

[8] Kahneman, D. and Tversky, A. (1973), "On the psychology of prediction”, Psychological Review, Vol. 80 No. 4, pp. 237-251.

[9] Baker, T., Miner, A.S. and Eesley, D.T. (2003), "Improvising firms: bricolage, account giving, and improvisational competency in the founding process", Research Policy, Vol. 32 No. 2, pp. 255-276.

[10] McLellan, H. (2006), “Corporate storytelling perspective”, The Journal for Quality and Production, Vol. 29 No. 1, pp. 17-20.

[11] Thier, K. (2006). Storytelling: eine narrative Managementmethode. Springer-Verlag.

[12] Kleiner, A., \& Roth, G. (1996). Field manual for a learning historian. MIT Center for Organizational Learning and Reflection Learning Associates.

[13] Thier, K. (2010). Storytelling. Eine Methode für das Change, Marken-, Qualitäts-und Wissensmanagement, 2., aktual. u. erg. Auflage. Springer-Verlag.

[14] Eppler, M.J., \& Platts, K.W. (2009). Visual Strategizing: The Systematic Use of Visualization in the Strategic-Planning Process. Long Range Planning, 42(1), 42-74.

[15] Eppler, M. J., \& Burkhard, R. A. (2007). Visual representations in knowledge management: framework and cases. Journal of knowledge management, 11(4), 112-122.
[16] Jarzabkowski, P. and Kaplan, S. (2015). Strategy tools-inuse: a framework for understanding 'technologies of rationality’ in practice. Strategic Management Journal, 36(4), 537-558.

[17] Meyer, R.E., Jancsary, D., Höllerer, M.A., \& Boxenbaum, E. (2017). The role of verbal and visual text in the process of institutionalization. Academy of Management Review.

[18] Kress, G., \& van Leeuwen, T. (2006). Reading images: The grammar of visual design (2nd Ed.). London et al.: Routledge.

[19] Höllerer, M. A., Jancsary, D., Meyer, R. E., \& Vettori, O. (2013). Imageries of corporate social responsibility: Visual re-contextualization and field-level meaning. Research in the Sociology of Organizations, 39(B), 139-174.

[20] Hill, C. A. (2004). The psychology of rhetorical images. In C. A. Hill \& M. Helmers (Eds.), Defining visual rhetorics, 25-40. New York: Routledge.

[21] Machin, D. (2004). Building the world's visual language: The increasing global importance of image banks in corporate media. Visual Communication, 3(3), 316-336.

[22] Gray, D. (2017). Empathy Map Canvas. http://gamestorming.com/empathy-map-canvas-006/.

[23] McKee, R. (1997). Substance, structure, style, and the principles of screenwriting. New York: HarperCollins.

[24] Sinek, S. (2009). Start with why: How great leaders inspire everyone to take action. Penguin.

[25] Duarte, N. (2013). Resonate: Present visual stories that transform audiences. John Wiley \& Sons.

[26] Gallo, C. (2010). The presentation secrets of Steve Jobs: How to be insanely great in front of any audience. Prentice Hall.

[27] Heath, C., \& Heath, D. (2007). Made to stick: Why some ideas survive and others die. Random House.

[28] Cayla, J., \& Arnould, E. (2013). Ethnographic stories for market learning. Journal of Marketing, 77(4), 1-16.

[29] Gollnofer, J. (2015). Ethnographic Approaches for Crafting Compelling Stories. Workshop on 'Storytelling in Sales \& Marketing’ given at Customer Insight Conference, Paris, October 7-9.

[30] D'Errico F, Signorello R, Demolin D, Poggi, I (2013). The Perception of Charisma from Voice: A Cross-Cultural Study. In Affective Computing and Intelligent Interaction (ACII), 2013 Humaine Association Conference on. IEEE. pp. 552557.

[31] Oatley, K., \& Johnson-Laird, P. N. (1987). Towards a cognitive theory of emotions. Cognition and emotion, 1(1), 29-50.

[32] Ekman, P. (2007). Emotions revealed: Recognizing faces and feelings to improve communication and emotional life. Macmillan.

[33] Brinker, K. (1988). Linguistische textanalyse. Dt. Blindenstudienanst..

[34] Roam, D. (2014). Show and tell: how everybody can make extraordinary presentations. Penguin UK.

[35] Field, S. L., Burlbaw, L. M., \& Davis Jr, O. L. (1994). "I Think There Was a Storm in the Desert”: Using Narrative to Assess Children's Historical Understanding of the Gulf War. The Social Studies, 85(6), 256-261.

[36] Campbell, J. (2008). The hero with a thousand faces (The collected works of Joseph Campbell). New World Library.

[37] Kahneman, D., Fredrickson, B. L., Schreiber, C. A., \& Redelmeier, D. A. (1993). When more pain is preferred to 
less: Adding a better end. Psychological science, 4(6), 401405.

[38] Reagan et al. (2016). The emotional arcs of stories are dominated by six basic shapes. EPJ Data Science, 5(1), 31.

[39] Eppler, M. J., \& Kernbach, S. (2016). Dynagrams: Enhancing design thinking through dynamic diagrams. Design Studies, 47, 91-117.

[40] Tonkinwise, C. (2011). A taste for practices: Unrepressing style in design thinking. Design Studies, 32(6), 533-545.

[41] Kernbach, S., Bresciani, S., \& Eppler, M. J. (2015). Slipsliding-away: A review of the literature on the constraining qualities of PowerPoint. Business and Professional Communication Quarterly, 78(3), 292-313.

[42] Kernbach, S., Eppler, M. J., \& Bresciani, S. (2015). The use of visualization in the communication of business strategies: An experimental evaluation. International Journal of Business Communication, 52(2), 164-187.

[43] Kernbach, S. \& Svetina Nabergoj, A. (2018). Visual Design Thinking: Understanding the role of knowledge visualization in the design thinking process. In Information Visualisation (iV), 2018 International Conference. 